\title{
PENGELOLAAN HUTAN MANGROVE BERBASIS KEARIFAN LOKAL DI DESA TIWOHO KECAMATAN WORI KABUPATEN MINAHASA UTARA PROVINSI SULAWESI UTARA
}

\author{
Juwita M. Sondakh ${ }^{1}$; Siti Suhaeni²; Martha P. Wasak ${ }^{2}$ \\ 1)Mahasiswa Fakultas Perikanan dan IImu Kelautan Universitas Sam Ratulangi Manado \\ 2)Staff Pengajar Fakultas Perikanan dan IImu Kelautan Universitas Sam Ratulangi Manado \\ Koresponden email : mariasondak48@gmail.com
}

\begin{abstract}
The purpose of this study was to examine community knowledge about the functions and benefits of mangrove forests, see the role of the Government in mangrove forest management and analyze the form of local wisdom of Tiwoho Village community in managing mangrove forests. The method used in this study is the survey method. The population in this study were all communities in Tiwoho Village. Retrieval of data using sampling method, while the method of taking samples using purposive sampling method. The samples taken were 33 people. Data collected are primary data and secondary data. Primary data is collected by means of observation and interviews guided by questionnaires, secondary data taken from the relevant agencies. Based on the results of the analysis it is known that: (1). The Tiwoho Village community $86.67 \%$ knew the functions and benefits of mangrove forests, only $13.33 \%$ did not know the benefits and functions of mangrove forests, (2). The government's role in managing mangrove forests is very good, with a yield of 4.07; (3). The Tiwoho Village community has excellent local wisdom in supporting mangrove forest management, with a yield of 4.19 .

Key Words: Characteristic, Ecotourism, Kasawari Village.
\end{abstract}

\begin{abstract}
Abstrak
Tujuan penelitian ini adalah untuk mengkaji pengetahuan masyarakat tentang fungsi dan manfaat hutan mangrove, melihat peran Pemerintah dalam pengelolaan hutan mangrove dan menganalisis bentuk kearifan lokal masyarakat Desa Tiwoho dalam mengelola hutan mangrove. Metode yang digunakan dalam penelitian ini adalah metode survey. Populasi dalam penelitian ini adalah seluruh masyarakat di Desa Tiwoho. Pengambilan data menggunakan metode sampling, sedangkan cara mengambilan sampel menggunakan cara purposive sampling. Sampel yang diambil sebanyak 33 orang. Data yang dikumpulkan adalah data primer dan data sekunder. Data primer dikumpulkan dengan cara observasi dan wawancara yang dipandu dengan kuesiner, data sekunder diambil dari instansi terkait. Berdasarkan hasil analisis diketahui bahwa: (1). Masyarakat Desa Tiwoho 86,67\% mengetahui fungsi dan manfaat hutan mangrove, hanya $13,33 \%$ yang belum mengetahui manfaat dan fungsi hutan mangrove, (2). Peran pemerintah terhadap pengelolaan hutan mangrove sangat baik, dengan hasil 4,07; (3). Masyarakat Desa Tiwoho memiliki kearifan lokal yang sangat baik dalam mendukung pengelolaan hutan mangrove, dengan hasil 4,19.
\end{abstract}

Kata kunci: Mangrove, Tiwoho Village, Local Wisdom

\section{PENDAHULUAN}

Hutan Mangrove merupakan ekosistem Cutama pendukung kehidupan yang penting di wilayah pesisir dan lautan. Selain mempunyai fungsi ekologis sebagai penyedia bagi biota perairan, tempat pemijahan dan asuhan bagi berbagai macam biota, penahan abrasi, amukan angin taufan, dan tsunami, penyerap limbah, pencegah intrusi air laut, dan lain sebagainya, hutan mangrove juga memiliki fungsi sosial dan ekonomis penting sebagai penghasil bibit/benih ikan, udang, kerang kepiting, telur burung, madu, dan lainnya sebagai kawasan wisata, konservasi, pendidikan dan penelitian (Dahuri $d k k$., 2001).

Indonesia tercatat setidaknya 202 jenis tumbuhan di hutan mangrove, meliputi: 89 jenis pohon, 5 jenis palma, 19 jenis pemanjat, 44 jenis herba tanah, 44 jenis epifit, dan 1 jenis paku (Noor, 1999). Menurut Kusmana (1999), jenis-jenis yang tumbuh di hutan mangrove antara lain: Rhizophora mucronata, Rhizophora apiculata, Bruguiera gymnorhiza, Ceriops tagal, Avicennia marian, Avicennia alba, Sonneratia alba, Sonneratia caseolaris, Xylocarpus granatum. Beberapa faktor utama penyebab kerusakan mangrove yaitu: 
pencemaran, konversi hutan mangrove yang kurang memperhatikan faktor lingkungan, dan penebangan yang berlebihan (Effendi, 2004) dan menurut Babo dan Froehlich (1998), kerusakan hutan mangrove karena dikonversi menjadi tambak.

Fungsi hutan bakau di wilayah pesisir bukan hanya penting sebagai pelindung fisik tetapi juga sebagai bagian terintegrasi dari eksositem wilayah pesisir lainnya, seperti ekosistem terumbu karang dan ekosistem padang lamun. Di Sulawesi Utara, hutan bakau sebagian besar telah rusak karena dikonversi menjadi lahan tambak dan pemukiman. Selain itu, pengambilan kayu bakau oleh masyarakat sekitar, untuk dijadikan kayu bakar merupakan penyebab lain kerusakan hutan bakau. Dengan demikian, berbagai aktivitas manusia memberi dampak pada kerusakan bakau (Pontoh, 2011).

Tingkat kerusakan ekosistem mangrove di dunia, termasuk Indonesia, sangat cepat dan dramatis. Ancaman utama kelestarian ekosistem mangrove adalah kegiatan manusia, seperti pembuatan tambak, penebangan hutan, pencemaran lingkungan, dan di samping itu terdapat pula ancaman lain seperti reklamasi dan sedimentasi, pertambangan dan sebabsebab alam seperti badai (Setyawan $d k k$., 2006).

Provinsi Sulawesi Utara dengan potensi mangrove yang cukup beragam juga mengalami masalah tingkat eksploitasi berlebihan tanpa adanya pengawasan dan kontrol. Pada tahun 1991 ekosistem mangrove di Sulawesi Utara tercatat 28.000 ha namun pada tahun 1997 luasannya telah berkurang menjadi 23.516 ha. Identifikasi di tahun 1999 luasan mangrove terus mengalami penurunan dan diperkirakan saat ini tersisa 4.833 ha (IPB, 2012).

Desa Tiwoho merupakan desa pesisir yang mempunyai hutan bakau (mangrove) seluas \pm 62.502 ha. Tahun 1991 Pemerintah melalui Kementerian Kehutanan menetapkan hutan mangrove Desa Tiwoho sebagai bagian dari kompleks Taman Nasional Bunaken (TNB). Bagi masyarakat Tiwoho, keberadaan mangrove sangat bermanfaat bagi keberlangsungan hidup mereka. Kawasan ini merupakan sumber ekonomi dan penyangga bagi masyarakat dari dampak negatif air laut. Namun penyangga kehidupan mereka mulai rusak pada tahun 1989 saat kawasan tersebut dikonversi menjadi tambak dan akibat buruk ini sangat dirasakan oleh masyarakat di Desa Tiwoho. Masyarakat Desa Tiwoho memiliki peran yang sangat besar dalam mengembalikan fungsi ekosistem kawasan mangrove Tiwoho (Kalitouw, 2015).

\section{METODE PENELITIAN}

Metode yang digunakan dalam penelitian ini adalah metode survei. Metode survei adalah suatu pengamatan atau penyelidikan yang kritis untuk mendapatkan keterangan yang baik terhadap suatu persoalan tertentu di dalam daerah atau lokasi tertentu yang dipolakan untuk memperoleh informasi yang dibutuhkan. Populasi dalam penelitian ini adalah seluruh masyarakat di Desa Tiwoho. Pengambilan data menggunakan metode sampling, sedangkan cara mengambilan sampel menggunakan cara purposive sampling. Sampel yang diambil sebanyak 33 orang yang terdiri dari 2 aparat desa, 10 orang petani, 10 orang nelayan, 10 orang pekerja serabutan, tokoh masyarakat 1 orang. Data primer dalam penelitian ini diambil dengan cara observasi dan wawancara yang dipandu dengan kuisioner yang dilakukan pada responden. Data sekunder adalah data yang dikumpulkan melalui pihak kedua, biasanya diperoleh melalui instansi yang bergerak di bidang pengumpulan data seperti Badan Pusat Statistik dan lain-lain (Arikunto, 2013). Data sekunder dalam 
penelitian ini diperoleh dari profil Desa Tiwoho.

Instrumen dalam penelitian ini digunakan untuk mengukur variabel yang diteliti. Skala pengukuran merupakan seperangkat aturan yang diperlukan untuk mengkuantitatifkan data dari pengukuran suatu variabel, dan untuk mencapai tujuan pertama menggunakan skala Guttman. Dari skala ini diperoleh jawaban yang tegas yaitu ya - tidak; benar - salah; pernah - tidak pernah; positif - negatif, dll. Tujuan kedua dan ketiga dicapai dengan menggunakan skala Likert. Skala ini digunakan untuk mengukur sikap, pendapat, dan persepsi seseorang atau sekelompok orang tentang fenomena sosial (Sugiyono, 1994).

Jawaban responden akan diberi skor untuk keperluan analisis secara kuantitatif dan skor untuk jawaban memakai skala Likert mempunyai gradiasi dari sangat positif sampai sangat negatif, misalnya:

1. Sangat Setuju/Selalu/Sangat Positif diberi skor 5

2. Setuju/Sering/Positif diberi skor

3. Ragu-ragu/Kadang-kadang/Netral diberi skor

4. Tidak Setuju/Hampir Tidak Pernah/Negatif diberi skor

5. Sangat Tidak Setuju/Tidak Pernah/Sangat Negatif diberi skor

\section{HASIL DAN PEMBAHASAN}

\section{Kondisi Hutan Mangrove}

Hutan mangrove di Desa Tiwoho memiliki luasan $\pm 62,502$ ha dan terdapat 16 jenis mangrove yang didominasi oleh Sonneratia alba, Rhizophora apiculata, Avicennia marina, Bruguiera gimnorrhiza, Ceriops tagal dan Nypa menurut salah seorang tokoh masyarakat yaitu Bapak Lorens Loho. Ada beberapa faktor terjadinya degradasi mangrove di desa Tiwoho yaitu di akhir tahun 1989 areal hutan mangrove tersebut dikonversi menjadi lahan tambak oleh sebuah perusahaan bernama PT. Wori Mas dan sekitar 20 ha hutan mangrove berubah menjadi tambak udang. Faktor lain yaitu masyarakat Desa Tiwoho memanfaatkan hutan mangrove sebagai kayu bakar untuk pembuatan batu bata, karena Desa Tiwoho dulunya merupakan penghasil batu bata.

Tahun 1991 pemerintah melalui Kementerian Kehutanan menetapkan hutan mangrove Desa Tiwoho sebagai bagian dari kawasan Taman Nasional Bunaken (TNB). Kebijakan ini merupakan konsekuensi dari amanah Undang Undang Nomor 41 Tahun 1999 tentang Kehutanan, di mana dalam Undang Undang tersebut/pada Pasal 2 disebutkan bahwa mangrove merupakan ekosistem hutan, oleh karena itu maka pemerintah bertanggungjawab dalam pengelolaan yang berasaskan manfaat dan lestari, kerakyatan, keadilan, kebersamaan, keterbukaan dan keterpaduan. Oleh karena itu masyarakat harus mentaati peraturan pengelolaan dan pemanfaatan mangrove sesuai dengan kaidah konservasi.

Pada tahun 1998, PT. Wori Mas membiarkan lahan tambak tersebut, sehingga Bapak Lorens Loho bekerjasama dengan LSM membentuk kelompok untuk mengelola kembali kawasan mangrove. Masyarakat Desa Tiwoho berpartisipasi mengembalikan dan menjaga kelestarian mangrove. Bapak Lorens Loho mendapatkan penghargaan dari Yayasan Lestari dan PEW Foundation dalam Lestari Award 2006 untuk kategori Penjaga Laut dan Pesisir. Pada tahun 2010 Bapak Lorens Loho juga mendapat penghargaan dari program TV SCTV dalam Liputan 6 Award 2010 untuk kategori Peduli Lingkungan Hidup.

Pada Tahun 2000an Honda berpartisipasi melaksanakan penanaman mangrove di Desa Tiwoho dan pada tahun 2016 sampai 2017 kunjungan dari perusahaan Indofood yang berpartisipasi untuk menanam mangrove dan pada bulan Mei 2017 kunjungan dari beberapa negara untuk penelitian mangrove dan lamun di Desa Tiwoho. Tahun 2018 semua mangrove 
sudah bertumbuh sehingga sudah tidak ada lahan lagi untuk menanam, menurut Pemerintah Desa Tiwoho yang menjadi prioritas saat ini dalam pengelolaan hutan mangrove yaitu menjaga kelestariannya karena hutan mangrove sangatlah berguna bagi masyarakat Desa Tiwoho khususnya yang berada di bagian pesisir dapat terhindar dari abrasi dan bagi masyarakat juga hutan mangrove mempermudah mendapatkan ikan dan kepiting.

\section{Pengetahuan Masyarakat tentang Fungsi dan Manfaat Hutan Mangrove}

Berdasarkan hasil analisis dengan skala Guttman diperoleh hasil bahwa masyarakat Desa Tiwoho 86,67\% mengetahui fungsi dan manfaat hutan mangrove. Masyarakat mengetahui bahwa hutan mangrove merupakan tempat mencari makan bertelur/memijah/beranak bagi berbagai jenis ikan, udang, kepiting, cumi, dll. Mereka juga mengetahui kalau hutan mangrove dapat mencegah abrasi, tsunami, gelombang besar, angin dan badai serta

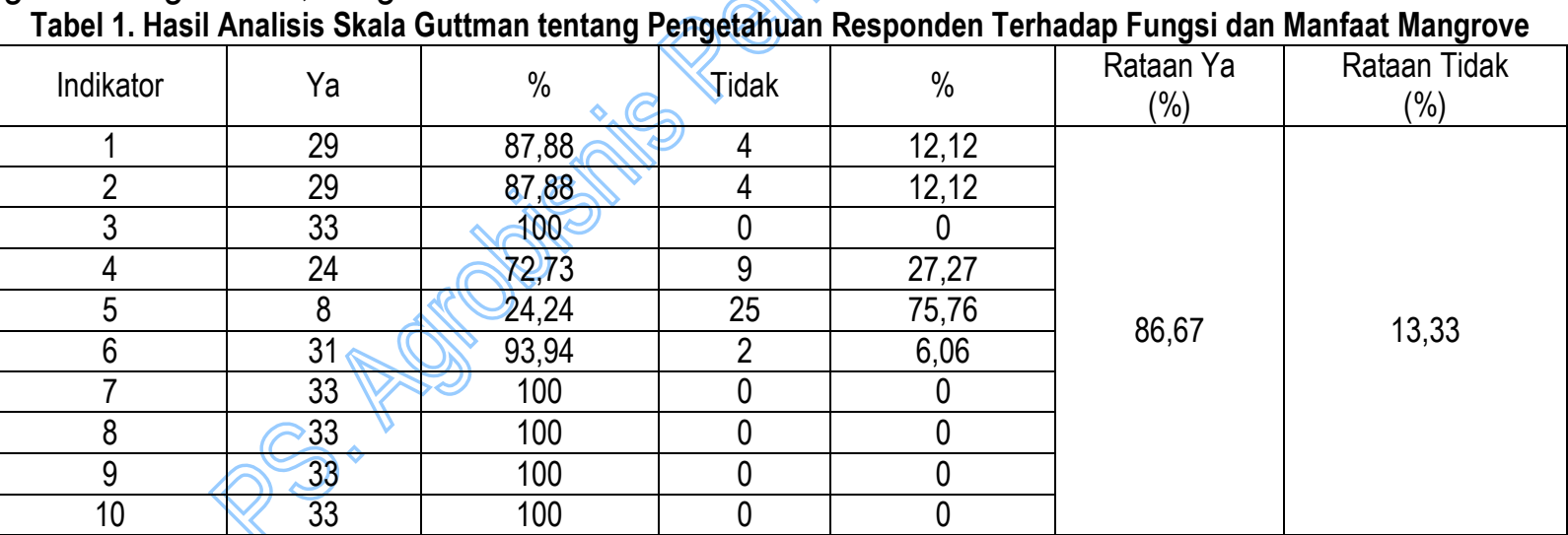

Sumber: Data Primer diolah 2019

\section{Peran Pemerintah Terhadap Pengelolaan Hutan Mangrove}

Berdasarkan hasil analisis dengan skala Likert diketahui bahwa peran pemerintah terhadap Pengelolaan Hutan Mangrove sangat baik menurut pandangan masyarakat Desa Tiwoho, hal ini terbukti dengan hasil rataan dimensi diperoleh hasil 4,07 yang berarti bahwa peran Pemerintah terhadap pengelolaan hutan mangrove merupakan perangkap sedimentasi dan juga menahan lumpur. Masyarakat menyadari kalau menebang pohon mangrove dapat merusak lingkungan sehingga mereka tidak berkeberatan adanya peraturan untuk tidak boleh menebang pohon mangrove. Masyarakat mengetahui kalau hutan mangrove di desa mereka merupakan wilayah dari Taman Nasional Bunaken yang dapat dijadikan tempat pariwisata.

Hanya sebagian kecil saja masyarakat Desa Tiwoho yang belum mengetahui manfaat dan fungsi hutan mangrove yaitu $13,33 \%$. Terutama mereka belum faham apa itu sedimentasi sehingga mayoritas tidan mengetahui kalau hutan mangrove merupakan perangkap sedimentasi. Hasil wawancara dengan responden, mereka mengatakan karena kata-katanya agak asing di telinga mereka dan agar lebih jelasnya hasil analisis skala Guttman tentang pengetahuan masyarakat Desa Tiwoho terhadap fungsi dan manfaat mangrove dapat dilihat pada tabel 1 berikut ini. 
beserta tokoh masyarakat dilakukan hampir di setiap kesempatan. Sosialisasi tentang mangrove ini juga diberikan pada anak-anak sekolah, hal ini dibuktikan dengan adanya mata pelajaran khusus tentang mangrove sebagai muatan lokal. Hal ini membuktikan keseriusan pemerintah dalam mengelola hutan mangrove yang ada di Desa Tiwoho. Sosialisasi yang dilakukan oleh pemerintah dan tokoh masyarakat diharapkan adanya kesadaran dari masyarakat supaya tidak merusak hutan mangrove karena mereka sadar akibat yang akan terjadi apabila hutan mangrove rusak.

Pemerintah daerah sudah melakukan sosialisasi tentang pengelolaan hutan mangrove kepada masyarakat, Pemerintah Daerah juga mengajak masyarakat memelihara, menjaga dan melindungi hutan mangrove karena fungsi dan manfaatnya yang begitu penting bagi masyarakat Desa Tiwoho. Tak lupa Pemda juga mengajak lembaga lain seperti LSM "Perkumpulan Kelola", lembaga keagamaan, lembaga swasta yang bersifat komersial juga untuk ikut serta berpartisipasi dalam pelestarian lingkungan dengan ikut andil dalam pengelolaan hutan mangrove. Dilibatkannya masyarakat membuat mereka merasa memiliki dan berkewajiban menjaga dan memelihara hutan mangrove. Berdasarkan hasil wawancara dengan aparat juga diketahui bahwa Pemda mengalokasikan dananya khusus untuk pengelolaan hutan mangrove. Agar lebih jelasnya hasil analisis skala Likert tentang peran pemerintah terhadap pengelolaan hutan mangrove di Desa Tiwoho dapat dilihat pada Tabel 2.

Tabel 2. Hasil Analisis Skala Likert Tentang Peran Pemerintah Terhadap Pengelolaan Hutan Mangrove

\begin{tabular}{|c|c|c|c|c|c|c|c|c|c|c|c|c|}
\hline \multirow{2}{*}{ Indikator } & \multicolumn{2}{|c|}{ Skor 1} & \multicolumn{2}{|c|}{ Skor 2} & \multicolumn{2}{|c|}{ Skor 3} & \multicolumn{2}{|c|}{ Skor 4} & \multicolumn{2}{|c|}{ Skor 5} & \multirow{2}{*}{$\begin{array}{l}\text { Rataan } \\
\text { Indikator }\end{array}$} & \multirow{2}{*}{$\begin{array}{l}\text { Rataan } \\
\text { Dimensi }\end{array}$} \\
\hline & $\mathrm{F}$ & $\%$ & $\mathrm{~F}$ & $\%$ & $\mathrm{~F}$ & $\%$ & $F$ & $\%$ & $\mathrm{~F}$ & $\%$ & & \\
\hline 1 & 0 & 0 & 0 & 0 & 3 & 9,09 & 28 & 84,85 & 2 & 6,06 & 3,97 & \multirow{10}{*}{4,07} \\
\hline 2 & 0 & 0 & 0 & 0 & 3 & 9,09 & 27 & 81,82 & 3 & 9,09 & 4.00 & \\
\hline 3 & 0 & 0 & 0 & 0 & 13 & 39,39 & 20 & 60,61 & 0 & 0 & 3,61 & \\
\hline 4 & 0 & 0 & 1 & 3,03 & 26 & 78,79 & 6 & 18,18 & 0 & 0 & 3,15 & \\
\hline 5 & 0 & 0 & 0 & 0 & (2) & 6,06 & 27 & 81,82 & 4 & 12,12 & 4,06 & \\
\hline 6 & 0 & 0 & 0 & 0 & 9 & 27,27 & 18 & 54,55 & 6 & 18,18 & 3,91 & \\
\hline 7 & 0 & 0 & 0 & 0 & 0 & 0 & 7 & 21,21 & 26 & 78,79 & 4,79 & \\
\hline 8 & 0 & 0 & 0 & 0 & 0 & 0 & 6 & 18,18 & 27 & 81,82 & 4,82 & \\
\hline 9 & 0 & 0 & 0 & 0 & 6 & 18,18 & 23 & 69,70 & 4 & 12,12 & 3,93 & \\
\hline 10 & 0 & 0 & 0 - & 0 & 0 & 0 & 19 & 57,58 & 14 & 42,42 & 4,42 & \\
\hline
\end{tabular}

Sumber: Data Primer diolah 2019

\section{Kearifan Lokal dalam Pengelolaan Hutan Mangrove}

Kearifan lokal adalah istilah yang diberikan bagi praktek-praktek pengelolaan sumberdaya alam oleh kelompok manusia yang dihasilkan dari interaksi dan adaptasi kelompok manusia dengan lingkungan alamnya. Pengelolaan sumberdaya alam oleh masyarakat sudah ada sejak dahulu secara turun temurun untuk menunjang kehidupan karena merupakan kebudayaan mereka.

Unsur budaya daerah potensial sebagai kearifan lokal karena telah teruji kemampuannya untuk bertahan.
Berdasarkan hal tersebut kearifan lokal adalah pengetahuan asli (indigineous knowledge) atau kecerdasan lokal (local genius) suatu masyarakat yang berasal dari nilai luhur tradisi budaya untuk mengatur tatanan kehidupan masyarakat dalam rangka mencapai kemajuan komunitas baik dalam penciptaan kedamaian maupun peningkatan kesejahteraan masyarakat. Kearifan lokal itu mungkin berupa pengetahuan lokal, keterampilan lokal, kecerdasan lokal maupun sumberdaya lokal.

Berdasarkan hasil analisis dengan skala Likert diketahui bahwa kearifan lokal yang mendukung dalam pengelolaan hutan 
mangrove sangat baik menurut pandangan masyarakat Desa Tiwoho, hal ini terbukti dengan hasil rataan dimensi diperoleh hasil 4,19 yang berarti bahwa kearifan lokal dalam pengelolaan hutan mangrove berada pada rentang yang positif dan skala penilaian yang sangat baik.

Masyarakat Desa Tiwoho mempunyai suatu kebiasaan untuk meminta ijin kepada aparat desa apabila ada kebutuhan untuk menebang pohon mangrove, karena ada peraturan tidak tertulis yang mengharuskan siapa saja anggota masyarakat Desa Tiwoho yang menebang pohon mangrove harus menanam 10 kali lipat banyaknya pohon yang ditebang, sehingga aparat harus mengetahuinya. Tanpa disadari masyarakat akan melarang siapa saja yang ketahuan menebang pohon mangrove, hal itu tidak ada yang menyuruh, mereka akan menanyakan sudah lapor apa belum, kalau belum mereka akan melarang dan melaporkannya kepada aparat. Mulanya ini merupakan anjuran aparat pemerintah dan tokoh masyarakat kepada anggota masyarakat, namun lama kelamaan menjadi sesuatu yang biasa dan menjadi budaya masyarakat setempat. Setiap anggota masyarakat merasa wajib memelihara, melindungi dan mengawasi hutan mangrove.
Selain itu kepedulian masyarakat yang sudah merupakan kearifan lokal dalam mengelola hutan mangrove diwujudkan dengan dimasukkannya pengelolaan hutan mangrove dalam kurikulum sekolah dari SD sampai SMP sebagai muatan lokal. Sejak dini anak-anak di Desa Tiwoho sudah dibekali dengan pengetahuan tentang betapa pentingnya hutan mangrove, karena fungsi dan manfaatnya bagi masyarakat Desa Tiwoho. Pembekalan dari kecil dan sosialisasi yang selalu dilakukan oleh tokoh masyarakat dan aparat meningkatkan kesadaran untuk menjaga kelestarian lingkungan. Hal itu juga meningkatkan minat masyarakat untuk menanam dan memelihara pohon mangrove, karena dari hasil wawancara diketahui bahwa mereka akan mengambil biji mangrove yang mereka temukan dalam perjalanan kemudian mereka tanam atau menyerahkannya kepada orang yang biasa melakukan pembibitan mangrove. Sesuatu yang tadinya terpaksa karena lama kelamaan menjadi suatu kebiasaan dan akhirnya melembaga menjadi budaya. Agar lebih jelasnya hasil analisis skala Likert tentang. Kearifan Lokal dalam Pengelolaan Hutan Mangrove di Desa Tiwoho dapat dilihat pada Tabel 3.

Tabel 3. Hasil Analisis Skala Likert Tentang Kearifan Lokal yang mendukung Pengelolaan Hutan Mangrove

\begin{tabular}{|c|c|c|c|c|c|c|c|c|c|c|c|c|}
\hline \multirow{2}{*}{ Indikator } & \multicolumn{2}{|c|}{ Skor 1} & \multicolumn{2}{|c|}{ Skor 2} & \multicolumn{2}{|c|}{ Skor 3} & \multicolumn{2}{|c|}{ Skor 4} & \multicolumn{2}{|c|}{ Skor 5} & \multirow{2}{*}{$\begin{array}{l}\text { Rataan } \\
\text { Indikator }\end{array}$} & \multirow{2}{*}{$\begin{array}{c}\text { Rataan } \\
\text { Dimensi }\end{array}$} \\
\hline & $F$ & $\%$ & F & $\%$ & $F$ & $\%$ & $F$ & $\%$ & $F$ & $\%$ & & \\
\hline 1 & 0 & 20 & 0 & 0 & 0 & 0 & 9 & 27,27 & 24 & 72,73 & 4,73 & \multirow{10}{*}{4,19} \\
\hline 2 & 0 & 0 & 0 & 0 & 0 & 0 & 9 & 27,27 & 24 & 72,73 & 4,73 & \\
\hline 3 & 0 & 0 & 0 & 0 & 0 & 0 & 4 & 12,12 & 29 & 87,88 & 4,88 & \\
\hline 4 & 0 & 0 & 1 & 3,03 & 0 & 0 & 11 & 33,33 & 22 & 66,67 & 4,67 & \\
\hline 5 & 0 & 0 & 5 & 15,16 & 14 & 42,42 & 10 & 30,30 & 4 & 12,12 & 3,39 & \\
\hline 6 & 0 & 0 & 0 & 0 & 1 & 3,03 & 6 & 18,18 & 26 & 78,79 & 4,76 & \\
\hline 7 & 0 & 0 & 3 & 9,09 & 23 & 69,70 & 7 & 21,21 & 0 & 0 & 3,12 & \\
\hline 8 & 0 & 0 & 0 & 0 & 14 & 42,42 & 19 & 57,58 & 0 & 0 & 4,15 & \\
\hline 9 & 0 & 0 & 0 & 0 & 9 & 27,27 & 24 & 72,73 & 0 & 0 & 3,73 & \\
\hline 10 & 0 & 0 & 0 & 0 & 9 & 27,27 & 24 & 72,73 & 0 & 0 & 3,73 & \\
\hline
\end{tabular}

Sumber: Data Primer diolah 2019

Dari tabel di atas dapat dilihat bahwa dari 10 indikator yang ditanyakan semua mempunyai nilai rataan antara 3 dan 5 yang berarti bahwa masyarakat
Desa Tiwoho mempunyai kearifan lokal yang baik bahkan sangat baik untuk mendukung pengelolaan hutan mangrove. Hal ini dibuktikan dengan nilai 
rataan dimensi yang lebih dari 4 yaitu 4,19 yang berarti sangat baik.

Berdasarkan hasil wawancara tokoh masyarakat (Bapak Lorens Loho) dan responden diketahui bahwa ada beberapa aturan yang tidak tertulis yang juga merupakan salah satu kearifan lokal dalam pemanfaatan/pengelolaan hutan mangrove yang ada di Desa Tiwoho di antaranya:

1. Masih diperbolehkan mengambil batang dan ranting kayu dari pohon mangrove yang sudah mati untuk dimanfaatkan sebagai kayu bakar atau keperluan lainnya.

2. Pengambilan/penebangan kayu untuk perlengkapan nelayan, tiang rumah, pembuatan pentas, dan kayu bakar jika ada pesta perkawinan atau kematian harus mendapat ijin dari aparat desa, yang kemudian akan dikenakan sangsi untuk menanam 10 kali lebih banyak dari pohon mangrove yang ditebang.

3. Penebangan/pengambilan

kayu mangrove untuk tujuan komersial/dijual tidak diperbolehkan

Berdasarkan hasil wawancara dengan tokoh masyarakat juga diketahui bahwa pada tahun 2000, masih ada masyarakat yang sering merusak mangrove dengan menebang untuk digunakan sebagai bahan bakar. Tahun 2005, Kelompok Tani "Lestari" dan Bapak Lorens selaku ketua kelompok bekerjasama dengan pemerintah melakukan pemeriksaan di rumah-rumah masyarakat Desa Tiwoho dan memberikan teguran serta himbauan kepada masyarakat yang masih menggunakan mangrove. Masyarakat Desa Tiwoho diberikan pemahaman tentang mangrove dan diajak untuk berpartisipasi menjaga dan memelihara mangrove serta tidak lagi mengambil pohon mangrove.

\section{KESIMPULAN DAN SARAN \\ Kesimpulan}

Berdasarkan hasil analisis dapat disimpulkan bahwa:

1. Masyarakat Desa Tiwoho 86,67\% mengetahui fungsi dan manfaat hutan mangrove, hanya $13,33 \%$ saja yang belum mengetahui manfaat dan fungsi hutan mangrove. Terutama mereka belum faham apa itu sedimentasi sehingga mayoritas tidak mengetahui kalau hutan mangrove merupakan perangkap sedimentasi. Mayoritas masyarakat mengetahui bahwa hutan mangrove merupakan tempat

mencari makan/bertelur/memijah/beranak bagi berbagai jenis ikan, udang, kepiting, cumi dil. Mereka juga mengetahui kalau hutan mangrove dapat mencegah abrasi, tsunami, gelombang besar, angin dan badai serta merupakan perangkap sedimentasi dan juga menahan lumpur.

2. Peran pemerintah terhadap pengelolaan hutan mangrove sangat baik, hal ini terbukti dengan hasil rataan dimensi diperoleh hasil 4,07 yang berarti bahwa peran Pemerintah terhadap pengelolaan hutan mangrove berada pada rentang yang positif dan skala penilaian yang sangat baik. Selain peran pemerintah juga terdapat peran tokoh masyarakat yang menonjol yaitu Bapak Lorens Loho yang selalu aktif dalam hal sosialisasi tentang manfaat dan fungsi mangrove kepada masyarakat serta mangrove dijadikan salah satu mata pelajaran di SD sebagai muatan lokal.

3. Masyarakat Desa Tiwoho memiliki kearifan lokal yang sangat baik dalam mendukung pengelolaan hutan mangrove, hal ini terbukti dengan 
hasil rataan dimensi diperoleh hasil 4,19 yang berarti bahwa kearifan lokal dalam pengelolaan hutan mangrove berada pada rentang yang positif dan skala penilaian yang sangat baik. Kearifan lokal yang menunjang pengelolaan hutan mangrove di Desa Tiwoho antara lain tebang 1 tanam 10, melarang dan menegur siapa saja yang menebang atau merusak hutan mangrove, serta siapapun yang menemukan bibit mangrove akan mengambil untuk ditanam atau diberikan ke orang yang biasa menanam mangrove.

\section{Saran}

Sangat disarankan agar Pemda setempat lebih intensif lagi dalam mensosialisasikan tentang fungsi dan manfaat hutan mangrove. Adapun disarankan agar Pemda, memasukkan kearifan lokal yang ada di Desa Tiwoho ke dalam Peratuan Desa, agar ada lembaga yang dapat menindak lanjuti barangsiapa yang melanggarnya. Selain itu kearifan lokal yang positif yang ada di Desa Tiwoho dimasukan dalam Peraturan Desa, sehingga ada hitam di atas putih dan ada legitimasi yang kuat serta jelas siapa yang mempunyai wewenang untuk memberikan sangsi pada setiap pelanggaran.

Pemerintah juga dapat lebih berperan lagi untuk menambah manfaat dan fungsi hutan mangrove yang ada di Desa Tiwoho dengan membuat tempat ekowisata tanpa merusak hutan mangrove yang ada, sehingga dengan adanya ekowisata hutan mangrove maka masyarakat akan mendapat tambahan penghasilan dengan memanfaatkan pengunjung yang datang, baik dengan berjualan kuliner maupun souvenir dan menyediakan tempat parkir bahkan kalau bisa penginapan.

\section{DAFTAR PUSTAKA}

Arief, A. 2003. Hutan Mangrove Fungsi dan Manfaatnya. Kanisius. Yogyakarta.

Arikunto, S. 2013. Prosedur Penelitian: Suatu Pendekatan Praktik. Jakarta: Rineka Cipta.

Ayatrohaedi. 1986. Kepribadian Budaya Bangsa (local genius). Jakarta: Pustaka Jaya.

Bengen, D.G. 2000. Pengenalan dan Pengelolaan Ekosistem Mangrove. Pusat Kajian Sumberdaya Pesisir dan Lautan IPB. 58 hal.

Bengen, Dietriech G. 2002. Sinopsis: Ekosistem dan Sumberdaya Alam Pesisir dan Laut Serta Prinsip Pengelolaannya. Cetakan Ketiga. Pusat Kajian Sumberdaya Pesisir dan Lautan. Institut Pertanian Bogor. Bogor.

Bengen D.G. 2004. Sinopsis "Ekosistem dan Sumberdaya Alam Resisir dan Laut Serta Prinsip Pengelolaannya". Pusat Kajian Sumberdaya Pesisir dan Laut Institut Pertanian Bogor. Bogor.

Creswell, John W. 2009. Research Design Pendekatan Penelitian Kualitatif, Kuantitatif, dan Mixed. Yogyakarta: Pustaka Pelajar. Penterjemah Achmad Fawaid.

Bahuri, R., Rais, J., S. P Ginting. Dan M. J Sitepu. 2001. Pengelolaan Sumberdaya Pesisir dan Lautan Secara Terpadu. Balai Pustaka, Bogor.

Hilmanto, R. 2012. Buku Penuntun Praktikum Manajemen Hutan Mangrove. Jurusan Kehutanan Universitas Lampung. Bandar Lampung.

Institut Pertanian Bogor. 2012. Strategi Rehabilitasi Ekosistem Mangrove: Studi Kasus Desa Tiwoho. Institut Pertanian Bogor Press. Bogor.

Kalitouw, WD. 2015. Valuasi Ekonomi Hutan Mangrove di Desa Tiwoho Kecamatan Wori Kabupaten Minahasa Utara. Jurnal Jurusan Sosial Ekonomi Pertanian. Fakultas Pertanian. Unsrat. Manado.

Lewis, RJ. 2001. Hawley's Condensed Chemical Dictionary. 14th Edition. John Wiley \& Sons, Inc. New York.

Mangkay, S., Harahab, N., Polii, B dan Soemarno. 2012. Analisis Strategi Pengelolaan Hutan Mangrove Berkelanjutan di Kecamatan Tatapaan, Minahasa Selatan, Indonesia. Universitas Brawijaya. J-PAL. 3 (1): 8-18.

Maya Puspita, 2017. Kearifan Lokal Dalam Pengelolaan Sumberdaya Pesisir dan Laut. UNDIP. Semarang. 
Noor, Y. R., M. Khazali, dan I.N.N. Suryadiputra. 1999. Panduan Pengenalan Mangrove di Indonesia. WI-IP/PKA. Bogor.

Notoatmodjo, S. 2010. Metodologi Penelitian Kesehatan. Jakarta: Rineka Cipta.

Pontoh, O. 2011. Peranan Nelayan Terhadap Rehabilitasi Ekosistem Hutan Bakau (Mangrove). Jurnal Perikanan dan Kelautan Tropis. Fakultas Perikanan dan IImu Kelautan. Unsrat. Manado

Sanudin dan A. H. Harianja. 2009. Kearifan Lokal dalam Pengelolaan Hutan Mangrove di Desa Jaring Halus Kabupaten Langkat Sumatera Utara. Jurnal Sosial Ekonomi. Vol. 9 (1). ISSN: 37-45.

Saparinto, C. 2007. Pendayagunaan Ekosistem Mangrove. Dahara Prize. Semarang.

Siti Suhaeni, Soemarno, Nuddin Harahap, S. Berhimpon. 2014. The Empowerment Model of Skipjack Tuna Fish (Cakalang Fufu) Processing Small Industry in Bitung City. Journal of Research in Environmental and Earth Science Volume 1 Issue 4 (2014) pp: 09-15.

Setyawan AD, Winarno K. 2006. Permasalahan Konservasi Ekosistem Mangrove di Pesisir Kabupaten Rembang. Jawa Tengah. Jurnal Biodiversitas.

Schaduw, JNW. 2015. Keberlanjutan Pengelolaan Ekosistem Mangrove Pulau Mantehage
Kecamatan Wori Kabupaten Minahasa Utara Provinsi Sulawesi Utara. Jurnal LPPM Bidang Sains dan Teknologi. Fakultas Perikanan dan IImu Kelautan. Unsrat. Manado.

Sondakh, S., Soemarno, N. Harahap, S. Berhimpon. 2014. The Development of a Livelihood Alternative Based on Marine Service in Manado City. Journal of Research in Environmental and Earth Science Volume 1 Issue 4 (2014) pp: 16-21.

Sugiyono. 1994. Metode Penelitian Administrasi. Bandung: Alfabeta.

Sugiyono. 2009. Metode Penelitian Kuantitatif, Kualitatif dan R\&D. Bandung: Alfabeta.

Supriharyono. 2000. Pelestarian dan Pengelolaan Sumber Daya Alam di Wilayah Pesisir Tropis. Jakarta: Gramedia.

Supriharyono. 2007. Konservasi Ekosistem Sumber Daya Hayati di Wilayah Pesisir dan Laut Tropis. Yogyakarta: Pustaka Pelajar.

Swenekhe Sandra Durand, Keppi Sukesi, M. Luthfi Rayes, and Zetly E. Tamod. 2014. Analysis of Community Participation in the Management

of Mangrove Ecosystems in Bunaken SubDistrict, Manado. Journal of Research in Environmental and Earth Science Volume 1 Issue 4 (2014) pp: 22-26. 


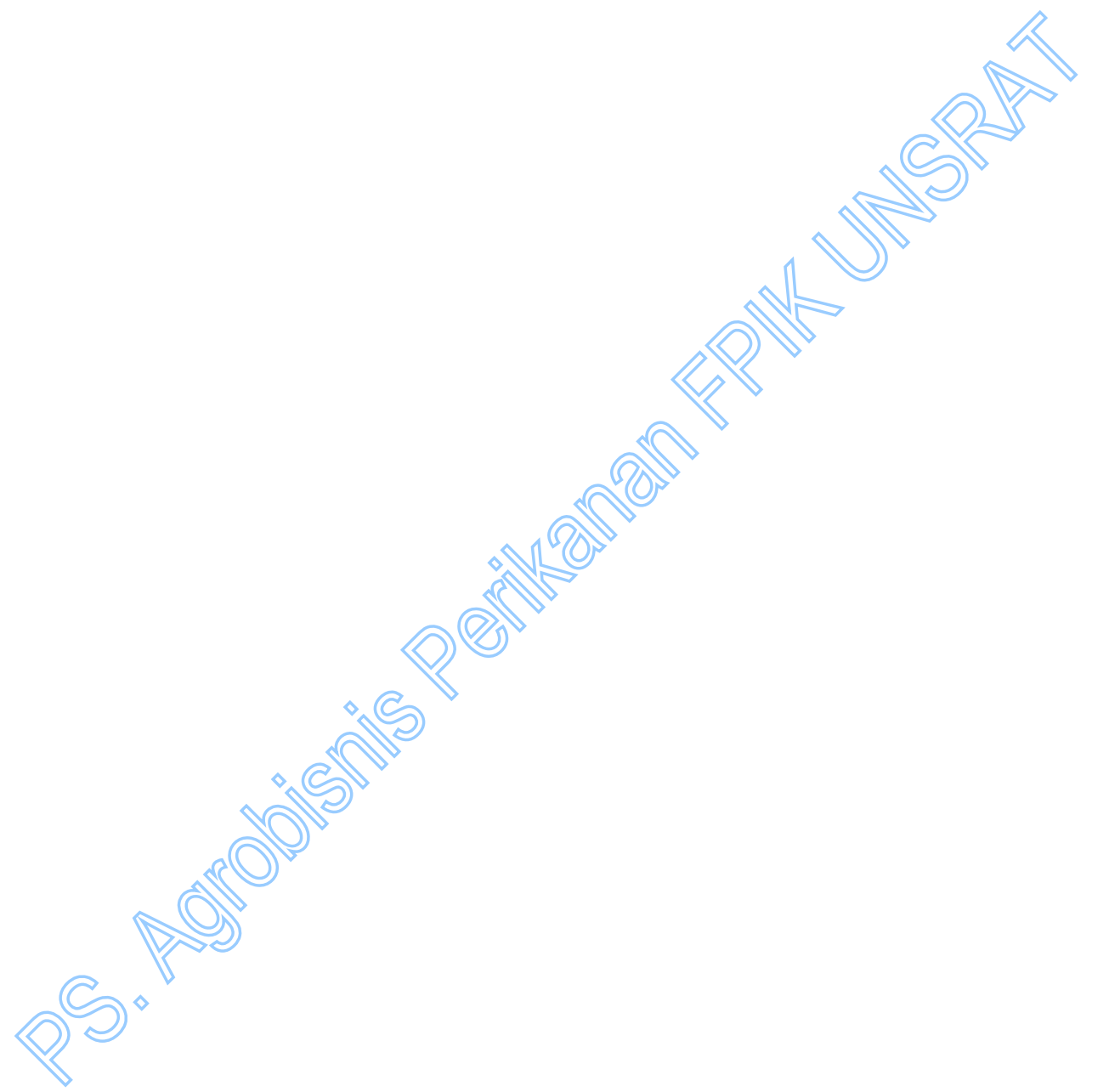

